\title{
PROPUESTAS METODOLÓGICAS PARA EL DISEÑO DE UN CURSO DE LENGUA EXTRANJERA BASADO EN EL ENFOQUE POR TAREAS. ANÁLISIS DE NECESIDADES, SELECCIÓN Y TIPOS DE TAREAS
}

\author{
METHODOLOGICAL PROPOSALS FOR THE DESIGN OF \\ A FOREIGN LANGUAGE COURSE BASED ON THE TASK \\ APPROACH. ANALYSIS OF NEEDS, SELECTION AND TYPES \\ OF TASKS
}

\section{Ernesto Ferrando Llimós*}

\begin{abstract}
RESUMEN
La puesta en práctica de un método o enfoque implica su materialización en una serie de materiales conducentes a alcanzar unos objetivos previamente establecidos, y que además deben de tener en cuenta unas necesidades, la de los discentes, también previamente definidas. Planteamientos tales como: qué pautas seguir en la elaboración de un curso basado en tareas, cuál es la mejor tarea, en qué partes se divide una tarea o cómo equilibrar significado y forma, entre otros, motivan respuestas que tratarán de ser respondidas en el presente artículo. En definitiva, este artículo se mueve de lo teórico o abstracto, a lo práctico y tangible. Trata sobre lo que toca el discente, sobre lo que aprende y sobre lo que es evaluado. Su intención es exponer las distintas propuestas actuales existentes para el diseño de las tareas que conforman un curso o currículo. Pretende ser, en definitiva, una ayuda al docente. Pero al margen de la diversidad de metodologías, se ha apostado y respaldado con la teoría de distintos autores, por un hilo conductor concreto que parte de situar al enfoque por tareas como medio didáctico a día de hoy irrenunciable, sobre todo en los enfoques CLIL (Content and Language Integrated Learning) o CBI (Content Based Instruction), a lo que se suma, además, unos factores creemos ineludibles en cualquier curso de lengua extranjera: incentivar la comunicación en clase, hacer del discente el centro de atención del proceso de aprendizaje, el enfoque orientado a la acción y la importancia de la función social en la enseñanza de lenguas extranjeras, así como de la inclusión de la interculturalidad.

Palabras clave: enfoque por tareas; curso; proceso; función social; interculturalidad.
\end{abstract}

\section{ABSTRACT}

The implementation of a method or approach implies its materialization in a series of materials conducive to achieving previously established objectives, and that must also take into account needs, that of students, also previously defined. This includes approaches

\footnotetext{
* Universidad Pablo de Olavide. Sevilla (España)

http://dx.doi.org/10.1590/010318138649737287421
} 
such as: what guidelines to follow in developing a course based on tasks, how a task can be best-shaped, parts of a task or how to balance meaning and form, among others. This article moves from the theoretical, or abstract, to the practical and tangible. It deals with what touches the student, what he learns and what is evaluated. Its intention is to expose the different existing proposals for the design of the tasks that make up a course or curriculum. It intends to be, in short, an aid to the teacher. But aside from the diversity of methodologies, it has been based, and supported by the theory of different authors, by a specific guiding principle that starts from the focus by tasks as a didactic means to this day that cannot be waived, especially in CLIL (Content and Language Integrated Learning) or $\mathrm{CBI}$ (content based instruction) approaches, plus some factors we believe to be unavoidable in any foreign language course: encouraging communication in the classroom, making the student the center of attention of the learning process, the action-oriented approach and the importance of the social function in the teaching of foreign languages, as well as the inclusion of interculturality.

Keywords: Task approach; course; process; social function; interculturality.

\section{PROPUESTAS METODOLÓGICAS. TIPOS DE PROGRAMAS Y ENFOQUES.}

Debido a las diversas variables que interactúan en la elaboración de un currículo, el profesional de la educación, cuya meta sea el desarrollo de la programación de un curso de lengua extranjera, tiene que saber que se enfrenta a una tarea francamente complicada. La consecución de los objetivos, según unas necesidades previas, su formalización a modo de materiales didácticos, y la posterior evaluación de los objetivos, representa para el docente un ejercicio que implica tener ciertos conocimientos y un tiempo siempre escaso. Cuestiones ineludibles como: ¿Cuáles son las necesidades de los discentes? ¿Se pueden conocer de antemano? ¿Qué enfoque tomar? ¿Qué teoría de la naturaleza de la lengua sostiene al método elegido? ¿Qué debe de primar la forma o el significado? ¿Cómo y cuándo se evalúa? entre otras, tratarán de ser respondidas, según los distintos estudios, en este tema. No obstante, conviene empezar por el principio.

En primer lugar hay que definir los términos. Se puede ver en los textos especializados términos como: programación, currículo, sílabo (traducción al español de "Syllabus") o curso. Por ejemplo, Sonsoles Fernández (FERNÁNDEZ, 2011, p. 6) habla de la programación como la materialización de los principios del currículo, mientras que para el Instituto Cervantes se refiere a: "el marco general de planificación, actuación y evaluación en el ámbito de la enseñanza y aprendizaje" (CVC-Currículo). Por su lado Álvaro García Santa-Cecilia (GARCÍA, 2008, p. 13), citando a Stern, le da al término currículo tres interpretaciones:

El currículo como un plan de estudios de un institución 
El currículo como el contenido de una asignatura

El currículo como la suma de factores como: los materiales, equipos, formación del equipo docentes, etc., todos ellos como parte del proceso de enseñanzaaprendizaje.

En síntesis, programa vendría a ser la ordenación (o concreción) de los contenidos que componen el curso o los cursos (incluyendo la relación entre metodología y contenidos, que se verá más adelante). Según lo expuesto, se infiere que es el curso lo que ven los discentes, sobre lo que trabajan, con lo que trabajan y de lo que son evaluados. En definitiva, programa es lo mismo que syllabus, el cual define Yalden, citando a Shaw, como el plan de acción, flexible en su construcción, que el docente convierte en realidad mediante la interacción en la clase (YALDEN, 1983, p. 19). Este término también ha sido definido por Santa-Cecilia, que vendría a ser lo que englobaría la organización de los contenidos (más parecido al concepto de programa), frente a método (o metodología, término más centrado en el diseño de cursos) como la selección y creación de las tareas/actividades del curso, puntualizando la estrecha frontera que existe entre ambos conceptos (GARCÍA, 2008, p. 15). A su vez, Martín Peris define currículo como:

(...) Se entiende por currículo el conjunto de decisiones y actuaciones relacionadas con la planificación y el desarrollo de la enseñanza en el marco de una determinada institución, fundamentado en un enfoque ${ }^{1}$ sobre la lengua y el aprendizaje. (Perís, 1998:99 en Pueyo y Martín, 2014: 17)

Como se puede ver, la definición de Martín Peris se acerca a la tercera de Santa-Cecilia. Por lo tanto, se podría decir que en el desarrollo de una propuesta didáctica se partiría de lo general (currículo, como marco general) a lo concreto (programa-curso).

Como cita Breen, las investigaciones sobre los desarrollos de programas ${ }^{2}$ son abundantes; desde Shaw, con su estudios en la década de los 70, hasta los más recientes como los de Wilkins, Raimes y Brumfit, entre otros, ya en los 80 (BREEN, 1987). Breen sostiene que en la actualidad existen dos tipos de programas de lenguas bien diferenciados por la visión que tienen del conocimiento y de su adquisición, ambos dentro de la categoría de programas proposicionales, a saber:

Programas formales, también llamado estructural o gramatical. En ellos la prioridad es el conocimiento el sistema de la lengua: la gramatical y sus aspectos

1. La negrita es nuestra. Este concepto se verá más adelante.

2. Se utilizará, por motivos de claridad expositiva, tanto programa como currículo. 
fonológicos, léxicos o morfológicos, es decir la forma antes que el significado, que se convierte en un mero apoyo.

Programas funcionales que se nutren de los estudios de los años 60 y 70, en el campo de la sociolingüística o de la pragmática. Básicamente, estos programas conciben la lengua como un medio para conseguir ciertos objetivos (saber hacer) en situaciones cotidianas, capacitando al discente a interactuar en situaciones concretas en la lengua meta, cuando la fluidez conduce a la corrección. La lengua ya no está dividida en reglas, sino en propósitos de uso (funciones). El más claro ejemplo de este tipo de programas se encuentra en el denominado como programa socio-funcional de Wilkins.

Otros autores han planteado otras divisiones. Por ejemplo, Santa-Cecilia, citando a Wilkins, establece esta división (GARCÍA, 2008, p. 15):

Programas sintéticos, los cuales, como los formales de Breen, dividen la lengua en sus reglas, y que para su enseñanza se establece un aprendizaje gradual, paso a paso, de estructura en estructura. Al final se supone que el discente tendrá una visión global del sistema lingüístico de la L2.

Programas analíticos, que frente a los anteriores la lengua se manifiesta sin control previo en donde el discente infiere las reglas de la L2. En este tipo de programas ubicaríamos los comunicativos y por supuesto el enfoque por tareas (NUNAN, 2011, p. 44)

Otra división la plantea Nunan, con dos tipos de programas:

Programas orientados al producto, como aquellos cuyo enfoque va dirigido a los conocimientos y aptitudes que los alumnos deberían obtener. En este tipo de cursos, los objetivos se plantean al empezar. Se centran en qué aprender.

Programas orientados al proceso, que frente a los anteriores, se centran en cómo estos mismos discentes aprenden; es decir, se dirigen hacia los procesos de enseñanza-aprendizaje que los conducen a un aprendizaje eficaz de la lengua, teniendo en cuenta las capacidades de cada discente. Los objetivos, en este tipo de programas, se marcan partiendo de una negociación previa entre los discentes y el docente.

En la misma línea, también White (1988, en GARCÍA 2008, p. 17) divide a los programas entre los que enseñan el "qué" de la lengua y los que se centran en el "cómo". Para Santa Cecilia los programas orientados al proceso aportan unas 
características concretas que los hacen especialmente adecuados para su aplicación al presentar una enseñanza basada en el discente, potenciando su autonomía (CVCEnfoque centrado en el proceso). Actualmente este tipo de cursos tiene una muy buena aceptación. Mientras para Breen los programas analíticos serían programas procesuales (o planes, como él los llama) que los define, en línea con White, como aquellos que representan cómo hacer algo, incluyendo tanto a los programas basados en tareas como los procesuales (o basados en procesos), aunque explica que no son la misma cosa:

(...) la programación procesual va más allá de los programas de aprendizaje mediante tareas proporcionando un puente entre el contenido y la metodología al ofrecer un medio para el programa real de un grupo/clase sea más accesible a cada uno de sus miembros. El programa procesual se centra en tres procesos: la comunicación, el aprendizaje y la actividad social intencionada de enseñanza y aprendizaje en un aula. (...) la prioridad fundamental del diseñador es proporcionar un marco de trabajo que permita al profesor y alumnos hacer las estas cosas por sí mismos y, por lo tanto, crear su propio programa en el aula de un modo progresivo y adaptativo. (BREEN, 1987)

No obstante, ha sido el enfoque por tareas, que se verá en este mismo artículo, el que más aceptación tiene en el ámbito de la enseñanza de idiomas.

\section{DEFINICIÓN DE LAS BASES METODOLÓGICAS PARA EL DESARROLLO DE UN PROGRAMA}

Hoy en día se puede decir que está ampliamente consensuado que un programa para la enseñanza de lenguas extranjeras debe de contemplar tres factores: el enfoque comunicativo (incluyendo el factor social e intercultural), la enseñanza centrada en el discente y la orientación a los procesos, más el factor social de la enseñanza y el factor intercultural de esta enseñanza. Seguidamente se desarrolla cada uno de estos puntos.

\subsection{El Enfoque comunicativo.}

Los programas actuales están claramente enfocados a capacitar al discente para una comunicación real. Dentro de los programas funcionales (según terminología de Breen) o los analíticos de Wilkins y a diferencia de los programas formales, el lenguaje como medio para la comunicación cobra una dimensión bien definida. Aparece el concepto amplio y un tanto ambiguo, de "competencia comunicativa" desarrollado por Hymes en los años 70, el cual recoge la importancia que dio Chomsky a las variables que influyen en la comunicación cotidiana de un 
hablante. Así pues, y ligado a esta idea, el concepto que plantea Hymes se refiere a la posibilidad que tiene el hablante para comunicarse eficazmente dentro de una determinada comunidad de habla. Es decir, el hablante debe saber cuándo hablar, cuándo no y de qué hablar, con quién, cuándo, dónde y en qué forma con su atención al factor sociocultural ambiental, frente a las concepciones de la lengua de corte formal que no tenían en cuenta estas variables. Con su teoría, Hymes cambió el punto de vista que se tenía de la concepción sobre el lenguaje:

Hay reglas de uso sin las cuales las reglas gramaticales serían inútiles. Del mismo modo que las reglas sintácticas pueden controlar aspectos de la fonología y las reglas semánticas quizá controlar aspectos de la sintaxis, las reglas de los actos de habla actúan como factores que controlan la forma lingüística en su totalidad ${ }^{3}$. (HYMES, 1972, p. 278 en CENOZ, s.f)

El planteamiento de Hymes abrió el camino a la inclusión de la faceta cultural en los programas, factor a día de hoy ineludible en cualquier programa de lenguas extranjeras. Otros autores complementaron las aportaciones de Hymes; Breen y Candlin en 1980 y Brimfit en 1984 (en BREEN 1987) indicaron que el lenguaje no es solo reflejar el conocimiento que uno tiene sobre las reglas y las convenciones de la lengua meta, sino que además ese hablante tiene que ser creativo con esas mismas reglas y convenciones, llegando al punto de negociarlas durante ese mismo proceso comunicativo. Es decir, la competencia comunicativa es un concepto dinámico, que se negocia (CENOZ, s.f). Es pues este un punto de inflexión para los modelos posteriores de programas.

Basándose en estas teorías, aparecen los programas nocio-funcionales como primer paso para el desarrollo de enfoques posteriores, basados en esa misma competencia comunicativa, pero que se verán enriquecidos con nuevos contenidos como los referentes culturales y saberes y comportamientos socioculturales o nuevas consideraciones sobre las habilidades del hablante con la inclusión de las habilidades y actitudes interculturales, facetas, todas ellas, fundamentales para el desarrollo de cualquier programa de lenguas actual.

\subsection{La enseñanza centrada en el discente.}

Concepto que nace de los estudios sobre el factor emocional y su influencia en el comportamiento de los individuos. En el campo de la didáctica es la base

3. La negrita es nuestra. Para Hymes, la corrección gramatical no es suficiente puesto que un hablante no solo tendrá en cuenta a la hora de hablar las reglas gramaticales de su idioma, sino que también considerará otros factores; por ejemplo el tipo de registro (ya vistos en el tema Metodología para la integración de contenido y lengua en este mismo trabajo) que usará para adaptarse al interlocutor. 
del enfoque humanístico: Hamachek dirá sobre este enfoque: "La educación humanística comienza con la idea de que los alumnos son diferentes y se esfuerza en ayudarles a que sean ellos mismos, más que a que sean los demás" (HAMACHEK, 1997, p. 149 en WILLIAMS y BURDEN, 2008, p. 45). De los mismos autores, de forma resumida, se puede detallar lo que este tipo de enfoque plantea:

a. Forma un sentimiento de pertenencia a un grupo

b. Hace que el tema sea relevante para el alumno.

c. Motiva el autoconocimiento.

d. Desarrolla la identidad del discente.

e. Incentiva la autoestima.

f. Tiene en cuenta los sentimientos de los discentes.

g. Proscribe la crítica en clase

h. Incentiva tanto el autoaprendizaje como la autoevaluación.

i. Estimula la creatividad y se puede decir que la curiosidad.

Todos estos puntos encajan perfectamente en una clase comunicativa (WILLIAMS y BURDEN, 2008, p. 47).

Los programas que focalizan su desarrollo en el discente han sido tenidos en cuenta por autores como Nunan, Breen, Santa-Cecilia o Martín Peris, entre otros. Nunan remarca la relación que hay entre la centralidad en el discente y la enseñanza comunicativa.

Mientras que el currículo centrado en el alumno tiene elementos similares al currículo tradicional, una diferencia clave es que la información sobre los alumnos y, si fuera viable, proveniente de los mismos, se va a incorporar en todas la etapas del proceso curricular, desde la planificación hasta la evaluación... (NUNAN, 2011, p. 29)

Nunan marca el principio de este, digamos, enfoque, en los estudios sobre estilos y estrategias de aprendizaje de Willing y Oxford, como en los relativos a la autonomía del discente de Benson (NUNAN, 2011, p. 30). Breen, por su lado, habla de la importancia de incluir al discente en su propio proceso pedagógico (BREEN, 1987).También Santa-Cecilia remarca, al hilo de los autores anteriores, la importancia que toma el discente en su propia formación:

La enseñanza centrada en el discente pone énfasis en la consideración de las necesidades, deseos y expectativas con respecto al qué y al cómo de la enseñanza y del aprendizaje. (...) desde el punto de vista de la enseñanza, la participación de los discentes es decisiva... (GARCÍA, 2008, p. 12) 
Martín Peris (PERIS, s.f, p. 1), mientras, ubica al discente en el tercer estrato del proceso enseñanza-aprendizaje formado por el objeto (el contenido, o sea, la materia a estudio), los procedimientos (las formas mediante las cuales los discentes acceden a ese objeto) y el sujeto (el propio discente). Este autor, en el mismo trabajo, propone una lista de principios generales para ser adaptados por el docente a la hora de desarrollar un programa centrado en el discente, que de forma sucinta se pueden desglosar en los siguientes puntos:

a. Presentar al discente actividades que representen una experiencia gratificante para el discente.

b. Hay que tener en cuenta la totalidad de la persona, desde lo racional a lo emocional.

c. Explotar la faceta creativa del discente.

d. Plantear tareas que permitan la una comunicación significativa entre los discentes y que además integren tanto las habilidades lingüísticas (leer, escribir, escuchar y hablar), como los niveles de la lengua (la gramática en sus distintas facetas, como la pragmática, el vocabulario, morfología, sintaxis sin olvidar la fonética).

e. Las actividades tienen que estar cerca del ámbito del interés del discente, sin olvidar las destrezas socioculturales.

f. Las actividades deben potenciar la autonomía del discente, estimulando la iniciativa en clase.

g. Estas tareas deben ser transparentes para el discente. Debe conocer el motivo a través de los objetivos que se marquen

h. El discente debe tratarse como una persona individual, con sus necesidades concretas.

\subsection{El enfoque orientado a la acción}

El Marco Común Europeo de Referencia (MCER) en 2002 vino a marcar el nuevo rumbo que debía tomar la enseñanza de idiomas en Europa, decantándose claramente por este enfoque ${ }^{4}$. La justificación se basa en la consideración del discente como un agente social, inmerso en un contexto concreto.

4. (...) Quizás, lo que resulta confuso es que hable (el MCER) de enfoque pero hay que tener en cuenta, como dice S. Llorián (2007p. 74) Llorián (2007 p. 74), que eso: «...no significa que desde el documento se defiendan o se tomen posturas dogmáticas relativas a teorías de adquisición y aprendizaje o sobre cómo debe afrontarse la enseñanza de la lengua. [...] Lo que hace el MCER es ofrecer un sistema de categorías y parámetros que posibilite la comunicación de los procesos y de los resultados del aprendizaje de una lengua entre profesionales y usuarios, en términos transparentes y coherentes para todos». (MELERO, s.f) 
El enfoque aquí adoptado, en sentido general, se centra en la acción en la medida en que considera a los usuarios y alumnos que aprenden una lengua principalmente como agentes sociales, es decir, como miembros de una sociedad que tiene tareas (no sólo relacionadas con la lengua) que llevar a cabo en una serie determinada de circunstancias, en un entorno específico y dentro de un campo de acción concreto. (MCER-Enfoque orientado a la acción).

A este respecto, Martín Peris precisa sobre este enfoque en relación con su importancia en el contexto actual de la didáctica de las lenguas extranjeras:

(...) que puede interpretarse (el enfoque orientado a la acción) como la versión más reciente de los enfoques comunicativos y su consolidación en nuestro espacio sociocultural. (...) concibe al alumno como usuario de la lengua, propiedad que descansa sobre un trípode: el alumno como agente social, como hablante intercultural y aprendiente autónomo. (PERIS, 2009 p. 7)

Es decir, el individuo para un correcto desempeño de función como hablante, necesita dominar una serie de competencias para poder desarrollar las actividades de la lengua.

El MCER las define como "las competencias comunicativas" ${ }^{15}$. Como referente, el MCER delimita los dos tipos de competencias: las competencias generales y las competencias lingüísticas, cuya diferencia sería:

Las competencias generales son las que no se relacionan directamente con la lengua, pero a las que se puede recurrir para acciones de todo tipo, incluyendo las actividades de lingüísticas.

Las competencias comunicativas son las que posibilitan a una persona actuar utilizando específicamente medios lingüísticos" (MCER-Enfoque orientado a la acción)

En el plano concreto de los contenidos, se podría, sucintamente, desglosar de esta manera (MCER 2002, p. 99-127):

\section{- Competencias generales}

- Conocimiento declarativo (saber $)^{6}$

o Conocimiento del mundo

- Conocimientos socioculturales

5. La RAE define a competencia como "Pericia, aptitud o idoneidad para hacer algo o intervenir en un asunto determinado" (RAE-Pericia).

6. De forma resumida representan los conocimientos sobre "lugares, instituciones, organizaciones, personas, objetos acontecimientos, procesos e intervenciones en distintos ámbitos; y, por otro, clases de entidades (concretas y abstractas, animadas e inanimadas, etc.)" (CVC-Competencias generales). 
○ La conciencia intercultural

- Capacidad de aprender (saber aprender)

- Reflexión sobre el sistema de la lengua y la comunicación

o Reflexión sobre el sistema fonético y las destrezas correspondiente

○ Las destrezas de estudio

- Las destrezas heurísticas (de descubrimiento y análisis)

- Competencias comunicativas de la lengua

•Competencias lingüísticas

○ Competencias léxicas

○ Competencia gramatical

o Competencia semántica

○ Competencia fonológica

○ Competencia ortográfica

○ Competencia ortoépica

-Competencia sociolingüística

o Los marcadores lingüístico de relaciones sociales

○ Las normas de cortesía

○ Las expresiones de sabiduría popular

$\circ$ Diferencias de registro

$\circ$ Dialecto y acento

-Competencia pragmática

o Competencia discursiva

o Competencia funcional

\subsection{La función social de la enseñanza y la interculturalidad.}

Hoy en día se asume como cierto y por tanto ineludible para la acción docente, que la educación debe estar enfocada a la formación de los ciudadanos del presente y del futuro; principio, por otro lado bastante discutido según el enfoque que se le 
imprima a esta idea. En definitiva, la variable social, y su inclusión en la metodología educativa, es un referente clave a la hora de analizar cualquier propuesta educativa, materializada en forma de programa (COLL et al: 1998, p. 131).

Partiendo de esta premisa, la relación entre la cultura y la lengua se ha ido paulatinamente materializando tanto en los currículos norteamericanos, por ejemplo, en los National Standars (1996) de los EEUU, en donde la lengua se contempla como un medio por el cual se aprende la cultura (EREIZAGA et al, 2005, p. 28), como dentro del ámbito europeo, como se verá más adelante.

La cultura fue poco a poco entrando en el proceso de enseñanza-aprendizaje de lenguas extranjeras a raíz de la aparición de los enfoques comunicativos con su intención de hacer que el discente consiga una capacidad comunicativa real. Para ello se entiende que el hablante debe de conocer el contexto sociocultural que lo envuelve. A este respecto, el Libro Blanco sobre el Diálogo Intercultural (2008) se presenta como uno de los documentos clave para entender el esfuerzo de las autoridades europeas a la hora de establecer unos criterios básicos dirigidos a potenciar la interculturalidad entre los miembros de la Unión. Como principios establece que:

A los efectos del presente Libro Blanco, por diálogo intercultural se entiende un proceso que abarca el intercambio abierto y respetuoso de opiniones entre personas y grupos con diferentes tradiciones y orígenes étnicos, culturales, religiosos y lingüísticos, en un espíritu de entendimiento y respeto mutuos. La libertad y la capacidad para expresarse, pero también la voluntad y la facultad de escuchar las opiniones de los demás, son elementos indispensables. (Libro Blanco, 2008, p. 3)

De forma clara, el documento muestra su completa determinación a superar divisiones entre los Estados ${ }^{7}$, en aras de una multiculturalidad basada en la democracia como modelo político irrenunciable, a través del diálogo intercultural entendido como: "un intercambio de opiniones abierto y respetuoso, basado en el entendimiento mutuo, entre personas y grupos que tienen orígenes y un patrimonio étnico, cultural, religioso y lingüístico diferentes" (Libro Blanco, 2008, p. 14).

Byram, al respecto, hace hincapié en la idea de intercambio comunicativo enfatizando la disposición a escuchar - que sustenta la filosofía del Libro Blanco, mostrando con ello, de forma inequívoca, una estrecha relación entre la enseñanza de idiomas y el desarrollo de lo que posteriormente se llamará competencia

7. El filósofo Carlos París lo define ejemplarmente: "...ha operado singularmente en el hombre la tendencia a ver al otro, lo diverso, bajo el signo de la rivalidad, de la competencia, de la hostilidad. O también como lo extraño, lo desconcertante: ya ridículo e inferior, ya terrible y sobrecogedor" (PARÍS, 1983, p. 16). 
intercultural $^{8}$, cuyo motor será el enfoque comunicativo de la enseñanza de idiomas (BYRAM, 2008, p. 123). Será este enfoque el que oriente las políticas educativas impulsadas por el Consejo Europea estableciendo así las bases de ese diálogo intercultural. Por tal motivo se establecieron políticas educativas dirigidas a incentivar el dominio de los idiomas como medio de intercambio cultural, como eje fundamental del diálogo comunicativo que hace referencia el citado documento. Es ya evidente que el conocimiento sobre uno mismo, al estilo de los métodos o enfoques anteriores, no tiene ya cabida por razones diversas, como cita la resolución europea para la cultura en lo referido a la promoción de la diversidad cultural y el diálogo intercultural, ya en el 2007:

- Fomentar la movilidad de artistas y otros profesionales del ámbito de la cultura.

- Promover el patrimonio cultural, concretamente facilitando la movilidad de colecciones e incentivando el proceso de digitalización, con objeto de mejorar el acceso del público a las diversas formas de las expresiones culturales y lingüísticas.

- Promover el diálogo intercultural como proceso sostenible que contribuye a la identidad europea, a la ciudadanía y a la cohesión social, incluso mediante el desarrollo de las competencias interculturales de los ciudadanos. (Libro Blanco, Consejo de Europa, 2007)

En el plano político, el diálogo intercultural impulsa y consolida la unión entre los Estados miembros, a la par que incentiva el desarrollo político de los mismos al permitir aprender el uno del otro (BYRAM, 2008, p. 124). En lo relativo a los idiomas, el Consejo de Europa, a través del Libro Blanco, se muestra decididamente dispuesto a impulsarlos como medio para descubrir otras culturas (Libro Blanco 2008, p. 35). La interacción, tras lo expuesto, en la que se ahondará más adelante, se muestra como el medio mediante el cual el discente entra en contacto con el diálogo intercultural; cuando interaccionamos percibimos y nos perciben a través de nuestras identidades sociales (TAJFEL, 1981, en BYRAM, 2009, p. 15).

No obstante, desde siempre se ha relacionado la calidad de la interacción con el conocimiento de la gramática y el vocabulario, cuyo objetivo no era otro más que llegar a dominar el idioma como un hablante nativo. Tras la introducción en los programas educativos de conceptos como la multiculturalidad o el diálogo intercultural ese mismo discente de lenguas extranjeras además tiene que ser

8. Se define competencia intercultural como: "Por competencia intercultural se entiende la habilidad del aprendiente de una segunda lengua o lengua extranjera para desenvolverse adecuada y satisfactoriamente en las situaciones de comunicación intercultural que se producen con frecuencia en la sociedad actual, caracterizada por la pluriculturalidad" (CVC-Competencia Intercultural). 
consciente de su propia identidad cultural y la de aquellos con quienes interactúa en clase o fuera de ella. Así surge el denominado "hablante intercultural", concepto desarrollado por Kramsch, que define como, según Byram y Zaráte (BYRAM y ZARATE, 1994, en BYRAM 2009, p. 15-16), aquel discente capaz de establecer lazos entre su propia cultura, con su crítica se podría añadir, y otras, de mediar y explicar la diferencia y, sobre todo, aceptar dicha diferencia.

Desde el punto de vista del docente, el aprendiente, a través del programa, debe de ser instruido en destrezas que van más allá de las clásicas dirigidas a alcanzar cierta destreza lingüística, como indica el Marco Común Europeo para las Lenguas, con su distinción entre las competencias generales menos relacionadas con la lengua y las competencias lingüísticas propiamente dichas, en su apartado sobre las competencias del usuario o discente (Marco Común 2002, p. 111). Tal distinción se estructuraría de la siguiente forma:

\section{Competencias generales}

o Conocimiento declarativo (saber).

- El conocimiento del mundo: lugares, instituciones, organizaciones, etc., como por ejemplo las características geográficas del país en que se habla el idioma.

- El conocimiento sociocultural. Por ejemplo: la vida diaria, las condiciones de vida, las relaciones personales, valores y creencias. La política y la relación. Los hechos históricos, tanto en lo relativo a los personajes históricos, como a la producción artística.

- Conciencia intercultural. Como indicativa de las similitudes y diferencias entre el "mundo de origen" y el "mundo de la comunidad objeto de estudio".

Las destrezas y las habilidades (saber hacer)

○ Las destrezas y las habilidades prácticas.

- Destrezas sociales, de la vida (bañarse, vestirse, etc.), profesionales, de ocio (aficiones, practicar deportes, etc.)

○ Las destrezas y las habilidades interculturales

- Sensibilidad cultural. Capacitad para relacionar la cultura de origen con la cultura extranjera. Capacidad de superar estereotipos.

La competencia "existencial" (saber ser) 
o Al margen de los conocimientos, la actividad comunicativa de los usuarios o discentes se ve afectada en factores del tipo cognitivos, valores éticos, actitud o factores personales. Todo ello debe orientar al docente a saber adaptarse a los rasgos de la personalidad del discente.

\section{La capacidad de aprender (saber aprender)}

○ La reflexión sobre el sistema de la lengua y la comunicación

o La reflexión sobre el sistema fonético y las destrezas correspondientes

○ Las destrezas de estudio

o Las destrezas heurísticas (de descubrimiento y análisis)

Este modelo descriptivo de los distintos saberes que el discente debe tener en cuenta para su completo desarrollo como hablante intercultural parte del trabajo de Zarate y Byram en 1997, el cual sirvió como modelo para el esquema siguiente (Figura 1), desarrollado por Byram (BYRAM 2008, p. 128).

\begin{tabular}{|l|l|l|}
\cline { 2 - 3 } \multicolumn{1}{c|}{} & $\begin{array}{l}\text { DESTREZAS } \\
\text { - Saber comprender: interpretar } \\
\text { y comparar }\end{array}$ & \multicolumn{2}{|c|}{$\begin{array}{l}\text { CONOCIMIENTOS } \\
\text { - Saberes: Conocimiento } \\
\text { sobre el "otro" y sobre "yo } \\
\text { mismo" }\end{array}$} & $\begin{array}{l}\text { EDUCACIÓN } \\
- \text { Saber comprometerse: evaluar } \\
\text { críticamente }\end{array}$ & $\begin{array}{l}\text { Saber ser: actitud receptiva y } \\
\text { curiosidad }\end{array}$ \\
\hline & $\begin{array}{l}\text { DESTREZAS } \\
\text { - Saber aprender/hacer: Adquirir } \\
\text { nuevos conocimientos y saber } \\
\text { aplicarlos }\end{array}$ & \\
\cline { 1 - 2 }
\end{tabular}

Figura 1.

De lo expuesto en el esquema se desprende que la EDUCACIÓN, ubicada en su centro, con su apuesta por la crítica, se convierte en la parte más importante dentro de lo que sería la enseñanza en valores relativos a la competencia intercultural, Byram recalca que la crítica cultural abre la mente del discente a la evaluación de las prácticas o productos tanto de la cultura propia como la del otro, enfatizando siempre la reflexión (BYRAM 2008, p. 128). 


\section{FASES DEL DESARROLLO DE UN PROGRAMA}

Partiendo de las premisas expuestas hasta aquí sobre el modelo actual de programa de lengua extranjera, es necesario ver ahora qué pasos se siguen en el desarrollo de una propuesta didáctica.

A partir de un enfoque para determinar el programa, algunos autores usaron el concepto de método como conjunto de procedimientos encaminados a aplicar ese enfoque a modo de materiales. Serán Richards y Rodgers, (RICHARDS y RODGERS, 1986, p. 28), quienes, partiendo de esta idea, desarrollaron su modelo de método tripartito mediante el cual un docente podía desarrollar su programa. Su método se dividía en: el enfoque (como base teórica), el diseño (en donde se detallan los objetivos) y el procedimiento (en donde entrarían las prácticas concretas tanto del docente como del discente). En el siguiente esquema (Figura 2), adaptado del original, se puede ver claramente la idea tripartita de método de Richards y Rodgers, el cual ha tenido gran aceptación en el desarrollo de programas.

\begin{tabular}{|l|l|l|}
\hline \multicolumn{1}{|c|}{ METODO } & \\
\hline \multicolumn{1}{|c|}{ ENFOQUE } & \multicolumn{1}{|c|}{ DISENO } & PROCEDIMIENTO \\
\hline $\begin{array}{l}\text { Teoría sobre la naturaleza de } \\
\text { la lengua (Descripción de } \\
\text { competencias y las estructuras } \\
\text { básicas). }\end{array}$ & $\begin{array}{l}\text { Objetivos generales yicas, prácticas y conductas } \\
\text { observadas cuando se utiliza } \\
\text { el método (tiempo requerido } \\
\text { para su aplicación, modelos de } \\
\text { interacción en clase, técnicas } \\
\text { estrategias usadas tanto } \\
\text { Teoría sobre el aprendizaje de } \\
\text { la lengua (Descripción de los de actividades, papel del } \\
\text { procesos tanto cognitivos como } \\
\text { psicolingüísticos del aprendizaje } \\
\text { y de las condiciones que } \\
\text { discente, papel del profesorente como por los } \\
\text { posibilitan estos procesos). }\end{array}$ & $\begin{array}{l}\text { Papel de los materiales) } \\
\text { discentes a la hora de aplicar el } \\
\text { método }\end{array}$ \\
\hline
\end{tabular}

Figura 2

No obstante, a partir de los años 80 del siglo pasado, el concepto de método entra en crisis por la cantidad de variables implicadas en el diseño de un programa; las nuevas teorías sobre el aprendizaje de segundas lenguas, como se ha visto en el apartado anterior, obligó a reconsiderar la idea de un método único como algo poco adecuado para el contexto actual. En definitiva, la idea de método, como algo fijo, se sustituye por los enfoques, más flexibles, conformados a través de procesos (CVC-Método). Seguidamente se verán las propuestas aplicadas actualmente en el diseño de programas. 
Para Santa-Cecilia (GARCÍA 2008, p. 19) la identificación de los procesos que intervienen en el desarrollo de un programa facilita la visión general del mismo. Se podría decir, que es la hoja de ruta del programa. A este respecto, el autor plantea el siguiente esquema (Figura 3).

\begin{tabular}{|ll|}
\hline 1) & Análisis de necesidades \\
\hline 2) & Definición de objetivos \\
3) & Selección y gradación de las actividades y materiales \\
\hline 5) & Determinación de procedimientos de evaluación \\
\hline
\end{tabular}

Figura 3.

A lo que el mismo autor añade como otras variables o factores a considerar:

Factores de entorno. Papel de la lengua en el entorno así como factores de carácter político y social. En este sentido, $\mathrm{M}^{\mathrm{a}}$ Luisa Regueiro incluiría: el centro, el entorno social, los discentes y sus necesidades así como su lengua meta. El nivel que tienen de la L2 y su relación con el MCER, así como cualquier otro condicionante para la programación (REGUEIRO, 2014, p. 15).

Factores relacionados con la situación de la enseñanza.

o Factores relacionados con los alumnos. En este punto hay que considerar al valor que le dan al docente o, por ejemplo, el nivel de importancia que le dan a la interacción en clase o su capacitación para el trabajo autónomo. En definitiva, la idea es definir el grado de tolerancia a cierto tipo de estilo de enseñanza y aprendizaje.

o Factores relacionados con la forma de plantear el curso. Aquí entraría a valorarse el grado de formación de los docentes.

- Los materiales didácticos, que aunque se concreten a nivel de programa es importante plantear qué tipo de materiales se va a usar (o diseñar). Por ejemplo, si se usarán las TICs o se usarán materiales textuales de fuentes auténticas. También se deben de tener en cuenta los medios 
disponibles, por ejemplo, si los discentes contarán con internet en el aula.

\subsection{Análisis de necesidades}

Pese a considerarse como la primera fase en el desarrollo de un programa ${ }^{9}$, lo cierto es que, por ejemplo, Santa-Cecilia considera que no siempre el análisis de necesidades es el punto de arranque del proceso de diseño (GARCÍA, 2008, p. 30), coincidiendo con Yalden, porque, quizás, no se conozcan (YALDEN, 1983, p. 101). También Castellanos remarca este detalle; incluso llega a indicar que no solo no es necesario partir de unas necesidades precisas para elaborar un curso, sino que puede llegar a ser perjudicial puesto que estas necesidades cambian, con lo que también debería cambiar el sistema de enseñanza y aprendizaje (CASTELLANOS, 2002, p. 3). En relación a esto último, Yalden, por ejemplo, aboga por un planteamiento inicial flexible y enfocado a dos variables: las necesidades comunicativas para la clase y aquellas otras destinadas al desempeño de sus profesiones ${ }^{10}$.

De esta forma queda claro que partir de un análisis de necesidades iniciales fijas puede ser poco práctico, lo cierto es que el docente tiene que empezar por algo y qué duda cabe que esto es el análisis de necesidades. Pese a las dudas ya expuestas, las ventajas que aporta dicho análisis inicial son importantes; sobre todo, la apuesta por la participación del discente y la responsabilidad de éste en su proceso de aprendizaje, hace del desarrollo de un curso una labor que tiene que ser abierta a la participación, al diálogo entre los discentes y el propio docente. Se podrían desglosar estas ventajas:

Permite organizar la clase partiendo de los objetivos y características de los discentes

9. Hilda Taba, ya en 1962, estableció los pasos a seguir en el desarrollo de un currículo en donde ya aparecía el análisis de necesidades en primer lugar (en CVC-Currículo):

10. Hay que tener en cuenta que Yalden desarrolla su propuesta didáctica basándose en el enfoque comunicativo, con la consideración añadida del trabajo de la Comisión Europea de 1971 sobre las necesidades que tenían los trabajadores intracomunitarios ya en una Europa que empezaba a derribar sus fronteras. Qué duda cabe que en un mundo globalizado como el actual, los planteamientos de Yalden, en particular en lo relativo a la movilidad geográfica de los trabajadores y discentes, siguen en vigor simplemente si se recurre al MCER: "Los usuarios del Marco de referencia pueden tener presente y, en su caso, determinar: Las tareas comunicativas en los ámbitos personal, público, profesional y educativo que el alumno tendrá que aprender a realizar, cómo se le capacitará para ello o qué se le exigirá al respecto" (MCER 2002, p. 58) 


\section{Define estos objetivos}

Partiendo de estos objetivos, permite al docente preparar los contenidos que forman el curso

Partiendo del anterior punto, de los contenidos se pasará a las tareas que van a realizarse en clase, adaptándolas a sus características.

Estos objetivos posibilitan una correcta evaluación, que como cita Castellanos (2002:12), debería no estar centrada en el resultado final, sino en el mismo proceso, es decir: la evaluación debe de servir para adaptar el proceso a las necesidades concretas del grupo.

Castellanos, citando a Richterich, (en CASTELLANOS 2002, p. 5 y CVCAnálisis de necesidades) divide en dos grupos el tipo de necesidades:

Las necesidades objetivas. Aquellas que se derivan de las condiciones sociales, educativas y culturales de los discentes. Su nivel de competencia de la lengua meta así como las que se refieren al uso que le darán (profesional, académico, etc.). Un trabajo de ineludible referencia en lo que se refiere al análisis de las necesidades objetivas, es el proyecto del Nivel Umbral (Threshold Level ${ }^{11}$ ) de los años 70, el cual definió grado mínimo de dominio que un aprendiente de lengua extranjera debe alcanzar para poder usarla en situaciones cotidianas tratando temas habituales. Partiendo de esta premisa, un programa debería tener en cuenta estas variables, como objetivos:

- Los actos de habla, en forma de nociones y funciones lingüísticas, que los alumnos habrían de ser capaces de realizar.

- Los papeles sociales que previsiblemente habrían de desempeñar.

- Los tipos de texto que deberían poder manejar.

- Los temas sobre los que habrían de ser capaces de expresarse comunicarse (leer, escribir, conversar, etc.)

- Las formas y estructuras lingüísticas, así como el vocabulario, que deberían conocer para poder hacer todo lo anterior. (CVC-Análisis de necesidades)

11.El Threshold Level tuvo una gran influencia en el desarrollo de materiales, en particular aquellos destinados a la enseñanza de una lengua extranjera para fines específicos. Como indica Castellanos (op.cit), la necesidad de enseñar a adultos una lengua extranjera que fuera de utilidad en su desarrollo profesional, fue el punto de partida del análisis de necesidades, y en concreto de los cursos de lengua extranjera para fines específicos. 
Las necesidades subjetivas. Aquellas relativas a los aspectos cognitivos y afectivos $^{12}$ de los discentes. Sobre este tipo de necesidades Santa-Cecilia (GARCÍA, 2008, p. 92) las define como factores de naturaleza psicológica que influyen en el discente en su forma de entender el proceso de aprendizaje. Estos factores interactúan con él y se plantean desde dos perspectivas: las que marca la propia idiosincrasia de los discentes, así como su propio estilo de aprendizaje. La primera indicaría el comportamiento que muestra el discente frente determinado tipo de aprendizaje, su confianza en sí mismo, la tolerancia a la ambigüedad o su capacidad para asumir riesgos. Mientras que lo referente al estilo de aprendizaje englobaría, por su lado, aquellas conductas indicativas de cómo el discente, de forma particular, aprende ${ }^{13}$. Con el auge actual del enfoque centrado en el discente, el análisis de las necesidades subjetivas ha cobrado una especial relevancia a la hora de desarrollar materiales.

Para finalizar este apartado, conviene hacer mención de los medios que el docente tiene a su alcance para recabar información sobre las necesidades de sus discentes. Castellanos desglosa los siguientes instrumentos, según su aplicación:

Pruebas de clasificación, adecuados para conocer el nivel de lengua de los discentes

> Pruebas de nivel, destinadas a conocer si se ha conseguido alcanzar cierto nivel establecido de antemano.

Cuestionarios. Si se usan al principio puede servir para seleccionar un temario o metodología. Pueden servir tanto para conocer las necesidades subjetivas como las objetivas. Se pueden usar al final del curso para conocer su grado de aceptación y eficacia a la hora de alcanzar los objetivos planteados

12. Stevick, en 1980, acuñó la siguiente frase "El éxito (en el aprendizaje de una lengua extranjera) depende menos de los materiales, técnicas y análisis lingüísticos y más de lo que sucede dentro de y entre las personas en el aula». Es decir, el éxito depende menos de las «cosas» y más de las «personas»" (en ARNOLD, 2006).

13. Sobre el estilo de aprendizaje Richards y Lockhart en 1994 (en GARCÍA, 2008, p. 97) plantearon características que pueden tener los discentes en relación con la percepción: visuales, auditivos, táctiles y cinésicos. También distingue aquellos discentes reflexivos frente a los impulsivos, aquellos más analíticos frente a los que perciben el problema de forma global, los extrovertidos frente los introvertidos, etc. (CVC-Estilo de aprendizaje). No obstante estos estilos de aprendizaje no son inmutables, sino que pueden cambiar con el tiempo. En métodos actuales, basados en tareas, el objetivo del docente es promover la autonomía del discente el cual mediante la realización de dicha tarea sea capaz de encontrar su propio estilo o creencias (LORENZO, 2006, p. 71) 
Entrevistas. Pueden servir como alternativa a los cuestionarios, con la ventaja de ser más cercanas al discente.

Diálogo o conversación en clase. Que partiendo de cualquier tema, puede ser un magnífico medio para recabar información por lo espontáneo de las intervenciones

La observación en clase. Usada tanto en el análisis de necesidades como en la propia investigación en clase, la observación es un magnífico instrumento para evaluar la propuesta didáctica, su metodología y sus materiales.

El diario del discente, como medio para que el propio discente vea sus progresos o sus faltas durante el desarrollo de las actividades, que entronca con la propia evaluación.

El diario del docente. Igual que el caso del diario del discente, el docente puede hacer un seguimiento de su propia trayectoria, como, a su vez, fuente de reflexión sobre su propio desempeño como enseñante.

\subsection{Definición de objetivos.}

Tras la definición de las necesidades, vendría marcar los objetivos, los cuales básicamente indicarían qué se quiere lograr al aplicar determinado programa; se podría decir que es la razón por la cual existe el programa, lo que serán capaces de hacer los discentes gracias a él, mediante el uso de la lengua meta ${ }^{14}$. Además, los objetivos están directamente relacionados con la evaluación, tema que tiene su apartado correspondiente. Para Regueiro (REGUEIRO, 2014, p. 40), la especificación de los objetivos permite plantear la acción pedagógica en dos niveles de concreción: los objetivos generales y los específicos. Santa-Cecilia (GARCÍA, 2008) indica que partiendo de las necesidades objetivas el discente definirá los objetivos generales en relación a los contenidos lingüísticos. Mientras que del análisis de las necesidades subjetivas, extraerá el modo en cómo orientar el proceso de enseñanza-aprendizaje. Partiendo de estas premisas y profundizando en ambos tipos de objetivos, se podría decir que:

14. Van Ek relacionó los objetivos con el proceder, con la capacidad de aprender a hacer algo que no se sabía hacer previamente: "Language-learning objectives, like other learning-objectives, are defined in terms of behaviour. The aim of learning is always to enable the learner to do something which he could not do at the beginning of the learning-process. This applies to physical ability, such as the ability to ride a bicycle, as well as to less directly observable abilities, such as the ability to appreciate the difference between a burgundy and a claret, or the ability to understand some scientific theory" (VAN EK, 1975, p. 12). 
Los objetivos generales, son de índole práctico y se dividen en una escala de niveles de competencia, como lo hace el MCER.

Los objetivos específicos indicarían de una forma más parcelada los objetivos generales. Por ejemplo: los discentes serán capaces de diseñar una ruta turística por la ciudad de Barcelona.

No obstante, esta división de los objetivos no es la única; es importante señalar que el MCER no habla de objetivos específicos, refiriéndose, más bien, a las destrezas comunicativas (comprensión oral, comprensión escrita, expresión oral y expresión escrita). En este caso, los objetivos podrían estar centrados en esas competencias comunicativas. Es importante señalar que los objetivos pueden ser definidos de distinta manera según el punto de vista adoptado, según indica SantaCecilia (GARCÍA, 2008, p. 39).

Pielho (1981, en RICHARDS y RODGERS, 1986, p. 71), por ejemplo, detalla por niveles los objetivos, a modo de objetivos generales ${ }^{15}$ :

Un nivel integrativo y de contenido (el lenguaje como medio de expresión)

Un nivel lingüístico e instrumental (el lenguaje como un sistema semiótico y objeto del aprendizaje)

Un nivel afectivo de relaciones interpersonales (el lenguaje como medio para expresar valores y juicios sobre los otros y sobre uno mismo)

Un nivel de necesidades de aprendizaje individual (aprendizaje correctivo basado en el análisis del error)

Un nivel general de objetivos extralingüísticos (el aprendizaje de la lengua en el currículo escolar)

Por su lado, Tyler, citado por Santa-Cecilia (GARCÍA, 2008, p. 39) considera que los objetivos se pueden plantear desde un enfoque, se puede decir, más holístico. Para Tyler los objetivos especificarían:

Las cosas que el docente debe hacer

15. Referente a los objetivos específicos, hay que tener en cuenta que en el enfoque comunicativo se asume que la enseñanza de la lengua reflejará las necesidades particulares de los aprendientes. Estas necesidades pueden estar contenidas dentro de las destrezas correspondientes a leer, escribir, escuchar o hablar, cada una de las cuales puede ser abordada desde una perspectiva comunicativa según el nivel de competencia del discente y sus necesidades comunicativas. 
Los contenidos del programa (o curso), con sus temas.

Los patrones de comportamiento a desarrollar: desarrollar el pensamiento crítico, por ejemplo.

Los tipos de conducta (u objetivos de conducta) que los discentes serán capaces de desarrollar al finalizar el curso. En este punto, Tyler entiende que definiendo estos tipos de conducta ya se estará atendiendo a las necesidades del discente, por lo que considera este punto vital para el desarrollo de todo el curso. Para tal fin, el desarrollador tendrá que definir qué actividades se le van a pedir al discente, en qué condiciones se realizarán y el nivel que debe alcanzarse para poderlas realizar.

Actualmente debido a los enfoques de corte humanista, como los enfoques centrados en el discente, la definición de los objetivos pasa por la negociación con los aprendientes, por su involucramiento en el desarrollo del programa, cobrando un especial sentido la fase de definición de objetivos. Por ejemplo, Bridley (en NUNAN, 1985 , p. 69) apuesta por este modo de definir los objetivos:

(...) it means that learners (provided they have participated in the process of setting objectives) know what they supposed to be learning and what is expected of them; it provides a constant means of feedback and on-going evaluation for both teacher and learner; and it provides a way of beginning the individualization of instruction.

Richards (1990, en GARCÍA, 2008, p. 41) indica otra forma de identificar los objetivos:

Objetivos basados en las microdestrezas, como aquellas habilidades funcionales que intervienen en las cuatro macrodestrezas (leer, escuchar, hablar, escribir)

Objetivos basados en contenidos, como aquel conjunto de conceptos y procedimientos que hay aprender para lograr los objetivos del programa.

Objetivos basados en el nivel de competencia. Por ejemplo, las competencias comunicativas que se pretenden alcanzar que incluirían tanto las relativas a la gramática como al uso de la lengua

Objetivos de proceso, como aquellos que marcan cómo los discentes realizarán determinada tarea. 


\section{ESTRUCTURA DE UNA UNIDAD DIDÁCTICA BASADA EN EL ENFOQUE POR TAREAS}

Gracias a la consolidación de los modelos bilingües o los aportes de otras ramas, como la psicología, el enfoque por tareas se ha convertido en el modelo fundamental para el desarrollo de programas lenguas extranjeras. Así pues, aunque las bases conceptuales son las mismas, aquellos modelos primigenios se modernizaron con la incorporación de nuevas investigaciones. En este último epígrafe se entra de lleno en la metodología para el diseño de unidades didácticas basadas en tareas, como fase última del desarrollo de un curso.

Como punto de partida y en el plano de lo general, James Raths, (en COLL at al, 1998, p. 128) planteó su propuesta de 12 principios, de base constructivista, los cuales se postulaban como un boceto de lo que debería ser una tarea; una propuesta, la de Raths, que no forzosamente estaba pensada para su uso en el campo de la didáctica de las lenguas, pero que bien pueden servir para este cometido. La propuesta de Raths, basada en la comparación entre lo que debe ser una tarea y lo que no, se desglosaría de la siguiente manera (en COLL at al, 1998, p. 128 y citado por CANDLIN, 1990, p. 10).

1. Una tarea es preferible a otra si permite al discente tomar decisiones sobre cómo desarrollarla.

2. Una tarea es preferible a otra si el discente forma parte activa durante su resolución.

3. Una tarea es preferible si hay un proceso intelectual: cuando el discente tiene que realizar una investigación para su resolución.

4. Una tarea es preferible a otra si le permite al discente interactuar con su realidad.

5. Una tarea es preferible a otra si puede ser realizada por discentes de diferentes niveles de capacidad, así como intereses distintos.

6. Una tarea es preferible a otra si obliga al discente a revisar una idea, ley, idea, etc., en un contexto nuevo.

7. Una tarea es preferible a otra si motiva al discente a examinar ideas que habitualmente son aceptadas por la sociedad.

8. Una tarea es preferible a otra si coloca tanto al docente como al discente en un nivel de éxito, fracaso o crítica.

9. Una tarea es preferible a otra si motiva al discente a reconsiderar y revisar sus esfuerzos iniciales (aprender a aprender).

10. Una actividad es preferible a otra si obliga al discente a dominar reglas, normas o disciplinas. 
11. Una tarea es preferible a otra si posibilita al discente a trabajar en equipo, participando en el desarrollo y consecución de la tarea.

12. Una tarea es preferible a otra si esta es relevante e interesante para los discentes.

Tras esta visión general de lo que debería representar una batería de tareas, conviene entrar más en detalle. Para ello se van a ver seguidamente distintas propuestas metodológicas, empezando por la de Peter Skehan.

Skehan se centró en proporcionar un marco general que sirviera a los docentes, como creadores de materiales. Además, su trabajo (traducido y revisado por Begoña Pérez López, en Pérez, 1996) trató de disipar cualquier duda que pudiera surgir en torno a este tipo de enseñanza, habida cuenta de que el mal diseño de una unidad podría significar una mala praxis del enfoque. Aprovechando los avances en psicología cognitiva, Skehan buscó un significado práctico en una serie de trabajos de distintos autores prestando una especial atención a ciertos factores que influyen en el aprendizaje de una lengua extranjera y su aplicación en el aprendizaje por tareas. Skehan no era partidario, frente a otros, de centrar únicamente el aprendizaje en la comunicación, sino que la forma debería siempre estar presente; sin un apoyo en la forma, el discente no avanza. Este era su planteamiento de partida. Skehan concluye que el docente tiene que basar sus tareas no únicamente en los procesos comunicativos (destrezas comunicativas propias de un hablante no nativo) sino también en aquellas otras que incentiven el uso correcto de la forma.

Otro ámbito de interés para Skehan fue la conciencia de que el discente está aprendiendo. La conciencia cobra tres sentidos: la conciencia como conocimiento, control y atención. Como conocimiento, esta idea la relaciona con la dicotomía forma-significado y como apoyo estableció que en un sistema basado en reglas puede convertirse en un buen patrón para usos posteriores. La conciencia aumenta la fluidez al automatizar los conocimientos, al reestructurarlos, además de ser provechosa puesto que fragmentos del lenguaje se pueden convertir en útiles unidades significativas. Para Shehan un sistema que no contemple las reglas conduce al fenómeno de la fosilización debido al uso continuado de estructuras erróneas. Partiendo de las fases, o procesos, comunicativos conocidos - input, procesamiento central y output -, Skehan remarcó que la clave está en que las tareas estén centradas en el desarrollo de la interlingua, a base de situaciones que permita el procesamiento de la información de entrada (Input). Por su lado, Car y Curren (1994 en PÉREZ, 1996, p. 3), contemplados por Skehan, prestan atención al nivel de dificultad de la tarea: para una tarea fácil, no será necesaria una instrucción explícita, frente a una difícil en donde sí que puede ser necesaria. 
Dentro de lo que sería el objetivo de una unidad basada en tareas, Skehan apuesta por plantear situaciones lo más cercanas posibles a cómo actuaría un hablante nativo en lo referente a corrección (uso correcto de la gramática, fonética, etc.), complejidad (elaboración de enunciados cada vez más complejos) y fluidez, como la movilización de todos los recursos lingüísticos para producir una comunicación correcta en tiempo real. Skehan remarca que una falta de complejidad aleja al discente del nativo o, por ejemplo una falta de fluidez o una fluidez baja, posiblemente debida a un exceso de instrumentación del lenguaje, conduce al discente a un pobre aprendizaje. Skehan propuso su modelo metodológico para diseñar una unidad basada en la resolución de tareas. En el esquema siguiente (Figura 4) ya se aprecia cómo se clasifican las tareas, como propuestas para actividades. La tarea final, que se verá en otras propuestas, aquí son post-tareas

\begin{tabular}{|l|l|l|}
\hline \multicolumn{1}{|c|}{ FASE } & \multicolumn{1}{|c|}{ OBJETIVO } & PROPUESTA DE ACTIVIDAD \\
\hline Actividades previas & $\begin{array}{l}\text { Activar el lenguaje necesario } \\
\text { para la realización de la tarea, } \\
\text { cuyo objetivo es incentivar la } \\
\text { reestructuración del conocimiento } \\
\text { previo }\end{array}$ & Trabajo de concienciación lingüística \\
\hline Durante la tarea & $\begin{array}{l}\text { Propiciar la comunicación y la la } \\
\text { forma }\end{array}$ & Elección de la tarea para el \\
\hline Post-tarea-1 & Evitar una excesiva fluidez & control de precisión \\
\hline Post-tarea-2 & Fomentar la exactitud & $\begin{array}{l}\text { Repates, análisis y pruebas } \\
\text { elementón de alguna tarea con }\end{array}$ \\
\hline
\end{tabular}

Figura 4.

Seguidamente se estudiarán las propuestas metodológicas de Dave Willis, Moore y Lorenzo, David Nunan y Sheila Estaire para el diseño y secuenciación de unidades didácticas basadas en tareas.

Willis, apoyándose en investigaciones (FOSTER, 1996, SKEHAN, 1996, en WILLIS, 2016, p. 160) sobre los beneficios de incluir una pre-tarea, sintetiza su planteamiento inicial, en el fondo, como se verá, reestructura su idea inicial en tres fases, más una de evaluación final:

\section{Pre-tarea}


- Como fase de planificación, que puede durar entre 5 y 10 minutos, que partiría de una exposición inicial del docente, con sugerencias sobre ideas para el desarrollo de la tarea, las necesidades lingüísticas, el tiempo que habrá disponible para realizar la tarea o, por ejemplo, si alguien de la clase tiene alguna experiencia o conocimiento sobre el tema. Willis, apuesta por dar cierta autonomía a los discentes; que sean ellos quienes planifiquen la tarea, que descubran qué van a necesitar, que conocimientos, van a tener que usar para realizarla. En esta fase, la precisión en el lenguaje no es importante.

Tarea. Para el desarrollo de su metodología, Willis propone (Figura 5) las siguientes tareas (WILLIS, 2016, p. 63-110):

\begin{tabular}{|l|l|}
\hline Hacer listas & $\begin{array}{l}\text { Tormenta de ideas, partiendo de un tema, buscar hechos } \\
\text { (en textos, internet, etc.) y listarlos. }\end{array}$ \\
\hline Ordenar y buscar & Secuenciar, categorizar y clasificar \\
\hline Comparar & Relacionar, buscar diferencias e igualdades \\
\hline Solventar problemas & $\begin{array}{l}\text { Textos incompletos, estudio de casos, puzles, problemas de } \\
\text { la vida cotidiana }\end{array}$ \\
\hline Compartir experiencias personales & Contar anécdotas, dar la opinión \\
\hline Tareas creativas & $\begin{array}{l}\text { Investigaciones históricas o sociales. Escritura creativa. } \\
\text { Proyectos multimedia }\end{array}$ \\
\hline
\end{tabular}

Figura 5.

Post-tarea

o En esta fase se puede plantear un resumen de la tarea, prestando atención a la forma, escribiéndola de nuevo o comentada desde otro punto de vista; volver a leer un texto o escuchar de nuevo una conversación, puede propiciar nuevas interpretaciones. Aquí, dependiendo de la confianza que tengan los discentes en sus destrezas, se puede plantear tareas en pequeños grupos o para toda la clase. Otra interesante opción que incluye Willis es repetir la tarea, apoyándose en investigaciones (BYGATE 2001, ELLIS, 2003, LYNCH y MACLEAN 2001, ESSIG 2005 y PINTER 2006, en WILLIS 2016, p. 170) las cuales remarcan las ventajas que conlleva repetir la tarea, pero desde diferentes patrones. La ventaja es que se motiva el uso de nuevo vocabulario y se incentiva la forma.

Evaluación y reflexión final 
o Al final del ciclo de la tarea, en la misma clase, dentro de la post-tarea o al comienzo de la siguiente unidad, Willis plantea la posibilidad de que la clase, en grupo o de forma anónima, escriban un comentario sobre lo que han visto, sobre qué han aprendido o qué les ha gustado y que no. El docente puede simplemente abrir un pequeño debate sobre estos asuntos, según el nivel de la clase. El objetivo de esta fase puede ser doble: por un lado realizar los ajustes necesarios en la programación y en el otro como medio de autoevaluación para los discentes

Una propuesta al respecto es Moore y Lorenzo (2015). El trabajo tenía como objetivo el desarrollo de materiales didácticos basados en tareas para su inclusión en un curso CLIL. El programa se fundamentaba en dos principios básicos: la enseñanza centrada en el discente y en la resolución de problemas como pedagogía. De forma resumida, el programa se dividía en estas tres fases:

\section{a) PRE-TAREA}

Revisión previa del tema / conceptos a través de actividades (por ejemplo, usando ejercicios de verdadero/falso o uniendo conceptos)

Introducción de aspectos culturales

Activar el léxico específico del contenido.

Definición de las funciones necesarias.

Establecer / negociar los criterios de evaluación.

\section{b) TAREA}

Simulaciones: debates, interviús, presentaciones, etc.

Resolución de problemas y presentación de las soluciones.

Comparar, resumir y evaluar.

Dibujar mapas.

Producir, por ejemplo textos.

\section{c) POST-TAREA}

Autoevaluación o Feedback evaluativo a nivel de grupo o de forma individual. 
Revisión de los conceptos.

Reflexión sobre las estrategias de aprendizaje.

David Nunan, por su lado, (NUNAN, 2011, p. 34) marca el punto de partida para la enseñanza de una L2 basada en tareas en el concepto de tarea del mundo real (citada ya, como se ha visto por Estaire y Zenón), según la propuesta de Michael Halliday y su Gramática Sistémica Funcional. En términos generales, Halliday establece los usos de la lengua en tres niveles o macrofunciones:

Intercambiar viene y servicios (Macrofunción de servicio o Transaccional)

Socializar con otros (Macrofunción social o interpersonal)

Para divertirse (Macrofunción estética)

A partir de estas tres macrofunciones, Nunan establece el punto de arranque para el diseño de tareas pedagógicas, las que divide en:

\section{Tareas de ensayo}

o Nunan parte de la base de la importancia que tiene el uso creativo de la lengua (frente a un uso reproductivo) puesto que de esta manera se usan las destrezas lingüísticas de forma integrada. Básicamente son tareas cuyo objetivo es hacer algo en clase que puede ser real fuera de ella, o sea, útil.

\section{Tareas de activación}

o Activan, como su propio nombre indica, las destrezas lingüísticas. No son tareas como las del tipo anterior puesto que su objetivo es activar las funciones y las estructuras del lenguaje, como: hacer sugerencias, mostrar acuerdo, etc., y no se basan en la realidad que puede vivir el discente

Para adquirir una lengua ambos tipos de tareas tienen que aparecer en la unidad didáctica. La propuesta metodológica de Nunan, difiere, no obstante, de interpretaciones fuertes del enfoque comunicativo (como apoyan KRASHEN y TERRELL), es decir, que la adquisición se realiza de forma subconsciente, por lo que la gramática no es necesaria. Para Nunan, pedirle al discente que produzca en una lengua aún desconocida, puede ser contraproducente, mientras que la atención a la forma, en cambio, una manera de darle seguridad. La solución pasa por presentar al discente las relaciones que hay entre forma, significado y uso. 
Así, la forma deberá ser tratada convenientemente, sin detrimento del significado, a base de tareas específicas (Tareas posibilitadoras). Nunan plantea este esquema (figura 6) general de la estructura de una unidad didáctica (NUNAN, 2011, p. 39).

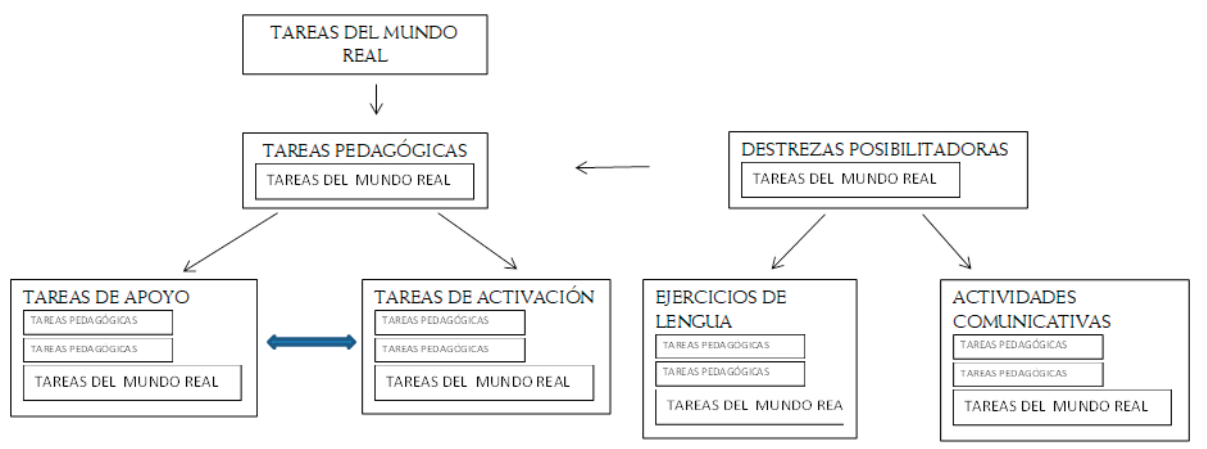

Figura 6.

En donde:

Ejercicios de lengua: Aquellos centrados en el léxico, en la fonética y en la gramática

Actividades comunicativas: A medio camino de los ejercicios de lengua y las tareas pedagógicas, cuyos objetivos y características se resumen en:

o Son similares a los ejercicios de lengua porque proporcionan una práctica manipulativa de una serie limitada de elementos lingüísticos

- Se asemejan a las tareas pedagógicas ya que tienen un elemento de comunicación significativa ${ }^{16} \mathrm{y}$ auténtica.

En lo relativo al encadenamiento de tareas, o secuenciación, Nunan propone unir las tareas de dos maneras, evitando en todo momento la aleatoriedad (NUNAN, 2011, p. 45-46).

Unir las tareas didácticas, o lecciones, mediante el principio de "encadenamiento de tareas", que se divide en seis apartados:

16. Se entiende aquí como comunicación significativa a aquella que es de interés del discente y responde a sus necesidades. Su objetivo es lograr algo que el hablante quiere o le interesa. Evidentemente no es una comunicación mecánica, puesto que el hablante habla por sí mismo. 
- Construcción de esquemas. En esta fase se presenta el tópico (o tema). Se establecen los contextos y las herramientas (vocabulario, estructuras, expresiones, etc.,) necesarias para realizar la tarea planteada. Se puede usar algún texto como ejemplo, en donde los discentes pueden empezar a ver las expresiones clave, como tarea.

- Práctica controlada. En esta fase los discentes realizan tareas que sirvan de práctica de lo visto en la fase previa. Se puede usar para la tarea un texto o audio y hacer que los discentes practiquen repitiendo lo leído o escuchado en parejas.

- Práctica auditiva auténtica. En esta fase se expone a los discentes a un texto audible de carácter auténtico. La tarea a realizar será pedirles que relacionen lo escuchado en esta fase con el texto usados anteriormente. Puede haber aporte de nuevo vocabulario.

○ Atención sobre los elementos lingüísticos ${ }^{17}$. Es el turno de la fase gramatical de la tarea. Como tarea se podría partir de los textos anteriores y pedir a los discentes que escriban preguntas y respuestas usando las estructuras vistas.

- Práctica libre. Aquí el discente es libre de producir sin las ataduras anteriores. Es el momento de improvisar. Los que improvisen estarán produciendo lo que Swain denomina como "input forzado" (SWAIN, 1995, en NUNAN 2011, p. 47) ya que para ellos la improvisación es un reto, un esfuerzo para lo cual deben usar todas las destrezas comunicativas o discursivas a su alcance. Esta fase es muy importante pues que es cuando su conversación se parece más a la de un nativo.

○ Presentación de la tarea pedagógica. Última fase en donde se presenta la tarea pedagógica que tendría la consideración de tarea final.

A un nivel más amplio, se puede unir las tareas mediante el tema (del curso, por ejemplo) o mediante las funciones o elementos gramaticales. A este respecto, Nunan aclara que un método perfectamente válido para organizar tareas podría ser el contenido de una asignatura, como la Geografía (NUNAN, 2011, p. 42).

17. Nunan desplaza la fase de atención a la forma a la cuarta fase. Su intención es que antes de llegar a esta fase, los discentes ya hayan leído, escuchado y hablado lo mínimo como para comprender la relación entre forma y significado. Como se verá más adelante, la propuesta metodológica de Estaire y Zenón difiere de lo que propone Nunan. 
Otra forma de plantear el desarrollo de unidades didácticas es la presentada por Sheila Estaire. Estaire reflexiona sobre cuál sería el punto de partida para el diseño de una unidad didáctica basada en tareas. Haciendo mención a Breen (1984, en ESTAIRE, 2011), Estaire señala que: "en el viaje del estudiante hacia la comunicación, la lista de contenidos tendría que construir el punto de llegada, y no de partida". Por lo tanto, los contenidos lingüísticos se desprenden de las tareas. Es decir, que partiendo de un tema, que conformará una batería de tareas, se plantearán aquellos contenidos lingüísticos necesarios para su realización. Estaire plantea dos tipos de tareas, que vienen determinados por la diferencia que hay entre el contexto del aula y el de la vida real. Las tareas se dividen en:

Tareas de comunicación. Activan los procesos de comunicación y constituyen la columna vertebral del enfoque. Este tipo de tareas ocupan la mayor parte del programa. Su característica fundamental es que están centradas en el significado y su objetivo es: "crear un contexto para el procesamiento comunicativo de la lengua, tratando la lengua como herramienta para la comunicación" (ELLIS, 2003, en ESTAIRE, 2011, p. 5). De esta manera se incentiva la construcción de la competencia comunicativa, cuyas características ya fueron comentadas en el epígrafe anterior.

Tareas de apoyo lingüístico. Que centradas en la forma (nociones, funciones léxico, etc.), vienen a dar soporte lingüístico a los contenidos de la unidad. Su objetivo es incentivar la corrección, más que la fluidez. Pueden haber sido diseñadas con antelación o pueden surgir de forma incidental, durante el proceso de realización de las tareas de comunicación (LONG, 1991, en ESTAIRE 2011, p. 67). Existen muchos tipos de tareas de apoyo lingüístico, por ejemplo:

- Las tareas de concienciación lingüística. Con puntos en común con las tareas de comunicación, las tareas de concienciación lingüística focalizan su atención en el tema de la tarea. Para ello deben de dar la oportunidad al discente de crear sus propias hipótesis, partiendo del descubrimiento y la reflexión, de los fenómenos lingüísticos (gramática, léxico, funciones, etc.) que se va encontrando. Para ello se suministra a los discentes información de la cual extraerán estos fenómenos usando para ello estrategias cognitivas: identificación, clasificación, comparación en un proceso continuo de descubrimiento y control de errores mediante la interacción que permite la búsqueda y análisis (por ejemplo, ejercicios de vacío de información). Es importante que los discentes tengan la oportunidad de aplicar lo 
aprendido de forma práctica (ELLIS, 2003, GÓMEZ de ESTAL y ZANÓN, 1999, en ESTAIRE, 2011, p. 68). En resumen, mediante el aprendizaje por descubrimiento y por resolución de problemas, estas tareas son especialmente indicadas.

o Ejercicios tradicionales. Por ejemplo, los de huecos, diálogos, etc., que tienen también su valor, sobre todo para automatizar el uso de ciertas estructuras.

A modo de estructura, ambos tipos de tareas deben de estar convenientemente combinadas de forma coherente en la unidad didáctica. Se habla ya de la secuenciación de las tareas, la cual se puede basar en dos modelos o procedimientos, según sea para cursos generales o específicos:

Partir del análisis de los intereses de los discentes, para pasar a los posibles usos o aplicaciones de la lengua, según su edad o nivel. Para ello Estaire plantea ámbitos como el familiar, el trabajo, el centro de estudio, etc. Los pasos siguientes serán plantear las tareas según los contenidos (ESTAIRE, 2011, p. 7).

Partiendo de las necesidades de los discentes (en cursos con fines específicos), pasar a plantear los posibles usos de la lengua, teniendo en cuenta los ámbitos (profesionales, público, etc.) y las acciones que los discentes tendrán que realizar dentro de ese ámbito. El siguiente paso será definir las tareas y sus contenidos.

El siguiente desglose refleja claramente el marco para la programación de una unidad.

a) Selección del tema y de la tarea final (que puede estar divididas en diversas sub-tareas). Para la tarea fina es tarea siempre comunicativa cuya finalidad es el desarrollo de la competencia comunicativa. Para su definición es recomendable que intervenga el discente.

b) Desglose de objetivos a partir de lo definido en a).

c) Desglose de los contenidos a partir de lo definido en a). Hay que tener en cuenta los contenidos nocio-funcionales, los contenidos gramaticales, ortográficos, sociolingüísticos. En general, las variables que engloban la competencia comunicativa.

d) Planificación de la secuencia de las tareas de apoyo lingüístico y de comunicación.

e) Posible revisión, o ajuste, de la tarea final, según el desarrollo de los puntos anteriores. 
f) Desarrollo de la evaluación, según criterios y procedimientos.

A la hora de programar la secuencia de tareas, dentro de la unidad didáctica, Estarie considera esencial cuatro variables:

1) La estructura de la programación de las tareas debe tener en cuenta: el tema, la tarea final, los objetivos y los contenidos, según el cuadro anterior

2) La realización de la tarea final es el objetivo de toda la unidad. Por lo tanto, las tareas deben de contemplar las capacidades y los contenidos necesarios para su realización.

3) Hay que prestar una especial atención a cómo interacción las tareas de comunicación con las de apoyo lingüístico. En este punto, en cierto modo como lo hace Nunan, Estaire aconseja que primero se empiece por algunas tareas comunicativas, que servirán como acicate para enfrentarse a las de apoyo lingüístico. Así, el discente verá la relación entre significado y forma.

En ningún caso en recomendable agruparlas; por un lado las tareas de comunicación y por el otro las de apoyo lingüístico.

4) Hay que integrar, de forma equilibrada, las cuatro destrezas comunicativas, siempre teniendo en cuenta el tipo de tarea final planteada.

\section{CONCLUSIONES}

En el presente artículo se ha tratado de exponer las directrices básicas para el diseño de un curso basado en el enfoque por tareas. Para ello, inicialmente, se ha centrado la exposición en las directrices sobre las que actualmente se fundamenta la teoría relativa la enseñanza de lenguas extranjeras: enfoque comunicativo, el enfoque humanista, con el discente como centro de atención del proceso de aprendizaje, el enfoque orientado a la acción, el factor social de la enseñanza de lenguas extranjeras y la interculturalidad como medio para conocer al otro, considerando el enfoque por tareas el más adecuado para aunar estos factores. Partiendo de este marco conceptual, se ha expuesto las distintas propuestas, según distintos autores, sobre la metodología para el diseño de cursos basados en tareas, en donde se ha podido ver cómo las tareas suelen dividirse en tres grandes bloques: pre tarea, tarea y post tarea, cada una con su función específica, partiendo de unas necesidades y objetivos concretos. 


\section{REFERÊNCIAS BIBLIOGRÁFICAS}

ARNOLD, J M. (2006). Los factores afectivos en el aprendizaje del español como lengua extranjera. Études de Linguistique Appliquée, n. ${ }^{\circ} 144 \mathrm{http}: / / \mathrm{cvc}$.cervantes.es/ensenanza/ biblioteca_ele/antologia_didactica/claves/arnold.htm (acceso el 24/12/2016)

BYRAM, M. (2008). Perspectivas interculturales en el aprendizaje de idiomas. Editorial Edinum. Colección Cambridge de didáctica de lenguas. Madrid.

BREEN, M. (1987). "Paradigmas contemporáneos en el diseño de programas de lenguas (I-II)». Signos. Teoría y práctica de la educación (1996-1997). (acceso el 5/52016) http://www.quadernsdigitals.net/index.php?accionMenu=buscador. http://www.quadernsdigitals.net/index.php?accionMenu=buscador.

VisualizaResultadoBuscadorIU.visualiza\&seccion $=8$ \&articulo_id $=687$ VisualizaRes ultadoBuscadorlU.visualiza\&seccion $=8$ \&articulo_id $=680$

CANDLIN, C, N. (1990). Hacia la enseñanza de lenguas basada en tareas. https://dialnet. unirioja.es/descarga/articulo/126204.pdf (acceso el 25/12/2016)

CASTELLANOS, I, V. (2002). Análisis de necesidades y establecimiento de objetivos MarcoELE. Didáctica del español como lengua extranjera. Expolingua. http:// marcoele.com/descargas/expolingua_2002.castellanos.pdf (Acceso el 22/12/2016)

CENOZ J, I. ( $\mathrm{s}, \mathrm{f})$. El concepto de competencia comunicativa. Centro Virtual Cervantes. http://cvc.cervantes.es/ensenanza/biblioteca_ele/antologia_didactica/enfoque_ comunicativo/cenoz02.htm (Acceso el 19/12/2016)

COLLI, C, MARTIN, E., MAURI, T., MIRAS, M., ONRUBI, J., SOLÉ,I. Et al (1998). El Constructivismo en el aula. Editorial Grao. Barcelona.

Consejo de Europa (2007). Resolución del Consejo: relativa a la mejora de la calidad y la diversificación del aprendizaje y de la enseñanza de las lenguas en los sistemas educativos de la Unión Europea. http://eur-lex.europa.eu/legal-content/ES/TXT/ PDF/? uri $=$ CELEX:31995Y0812(01)\&from $=$ ES (acceso el 16/09/2016).

CVC-Análisis de necesidades. Diccionario de términos clave de ELE. http://cvc.cervantes. es/ensenanza/biblioteca_ele/diccio_ele/diccionario/analisisnecesidades.htm (acceso el 24/12/2017) 
CVC-Competencias generales. Diccionario de términos clave de ELE. http://cvc.cervantes. es/ensenanza/biblioteca_ele/diccio_ele/diccionario/competenciasgenerales.htm (acceso el 12/12/2016)

CVC-Competencia Intercultural. Diccionario de términos clave de ELE http://cvc. cervantes.es/ensenanza/biblioteca_ele/diccio_ele/diccionario/compintercult.htm (acceso el 12/12/2016)

CVC-Currículo. Diccionario de términos clave de ELE http://cvc.cervantes.es/ensenanza/ biblioteca_ele/diccio_ele/diccionario/curriculo.htm (acceso el 17/12/2016)

CVC-Enfoque centrado en el proceso. Diccionario de términos clave de ELE. http://cvc. cervantes.es/ensenanza/biblioteca_ele/diccio_ele/diccionario/enfoqueproceso.htm (acceso el 18/12/2016)

CVC-Método. Diccionario de términos clave de ELE. http://cvc.cervantes.es/ensenanza/ biblioteca_ele/diccio_ele/diccionario/metodo.htm (acceso el 18/12/2016)

EREIZAGA, E. GOMEZ, I. IBARRA, E. (2005). El componente cultural en la enseñanza de lenguas como línea de investigación. Revista de Psicodidáctica.

ESTAIRE, S y ZENÓN, J. (1990). El diseño de unidades didácticas en L2 mediante tareas: principios y desarrollo. Centro Virtual Cervantes http://cvc.cervantes.es/Ensenanza/ biblioteca_ele/antologia_didactica/enfoque01/estaire_zanon01.htm (acceso el 1/01/2017)

ESTAIRE, S y ZENÓN, J. (1990). El diseño de unidades didácticas mediante tareas en la clase de español. MarcoELE. Antología de los encuentros internacionales del español como lengua extranjera. Las navas del marqués. http://marcoele.com/descargas/ navas/21.zanon-estaire.pdf (acceso el 07/01/2017)

ESTAIRE, S (2007). La enseñanza de lenguas mediante tareas: principios y planificación de unidades didácticas. Faea. http://www.nebrija.es/espanolparainmigrantes/flash/ ensenar/PDF/articulo-tareas.pdf (acceso el 22/12/2017)

ESTAIRE, S. (2011). Principios básicos y aplicación del aprendizaje mediante tareas. Marco ELE. Revista de Didáctica del español como lengua extranjera. http://marcoele.com/ principios-basicos-del-aprendizaje-mediante-tareas/ (acceso el 10/11/2016)

FERNANDEZ, S. (2011). Nuevos desarrollos y propuestas curriculares. Programar a partir del MCER. MarcoELE. Número 12. http://marcoele.com/descargas/12/fernandezprogramar.pdf (acceso el 10/11/2016) 
GARCÍA, SC, A. (2008). Cómo se diseña un curso de lengua extranjera. Cuadernos de Didáctica del Español/LE. Editorial Arco/Libros S.L. Madrid.

LIBRO BLANCO (2008). Libro Blanco sobre el Diálogo Intercultural.Vivir juntos con igual dignidad. http://www.coe.int/t/dg4/intercultural/Source/Pub_White_Paper/ WhitePaper_ID_SpanishVersion.pdf (acceso el 10/12/2015)

LORENZO, F B (2006). Motivación y segundas lenguas. Cuadernos de Didáctica del Español/LE. Editorial Arco/Libros S.L. Madrid.

MCER-Enfoque orientado a la acción (S.F). Centro Virtual Cervantes. http://cvc.cervantes.es/ ensenanza/biblioteca_ele/marco/cap_02.htm\#p21 (acceso el 20/12/2016).

MCER (2002). Marco común europeo de referencia para las lenguas: aprendizaje, enseñanza, evaluación. Centro Virtual Cervantes http://cvc.cervantes.es/ensenanza/biblioteca_ele/ marco/cvc_mer.pdf (acceso el 1/5/2016)

MELERO, P A. (s.f).Enfoque Comunicativo. Centro Virtual Cervantes. http://cvc.cervantes. es/ensenanza/biblioteca_ele/antologia_didactica/enfoque_comunicativo/ introduccion01.htm (acceso el 19/12/2016).

MORRE, P y LORENZO, F. (2015). Task-based learning and content language integrated learning materials design: process and product. The Language Learning Journal. Routledge.

NUNAN, D. (2011). La enseñanza de lenguas basada en tareas. Editorial Edinumen. Madrid.

NUNAN, D. (1985). Syllabus Design. Language Teaching: A Scheme for Teacher Education http://faculty.mu.edu.sa/public/uploads/1413270476.17460,680,Syllabus\%20Design.pdf (acceso el 1/12/2016).

PARÍS, C. (1983). El rapto de la cultura. Editorial Laia. Barcelona.

PERIS, M, E. (2009). Modelos pedagógicos y praxis en el aula. Ponencia presentada en el Simposio 25 Años de ELE, organizado por el Instituto Cervantes. https:// cuadernosdelprofesor.files.wordpress.com/2012/09/u-0-03-introduccic 3b3nmodelos-pedagc3b3.pdf (acceso el 20/12/2016)

PÉREZ, B, L. (1996). Un marco para la implementación de la enseñanza mediante tareas de Pere Skehan. Centro Virtual Cervantes. http://cvc.cervantes.es/ensenanza/biblioteca_ ele/antologia_didactica/enfoque01/skehan01.htm (acceso el 20/12/2016) 
PÉREZ, B, L. (2006). El diseño de cursos de lenguas basados en tareas de Rod Ellis. Centro Virtual Cervantes. http://cvc.cervantes.es/Ensenanza/biblioteca_ele/antologia_ didactica/enfoque01/ellis01.htm (acceso el 20/12/2016)

PUEYO, S y MARTÍN, I. (2014). Creación, adaptación y evaluación de materiales y recursos. Fundación Universitaria Iberoamericana (FUNIBER). Curso de Lingüística Aplicada al español como segunda lengua.

RAE-Pericia. Diccionario de la Real Academia Española. http://dle.rae. es/?id=AofanvT $\mid$ AogTnnL (acceso el 20/12/2016)

REGUEIRO, Ma L. (2014). La programación didáctica ELE. Pautas para el diseño de la programación de un curso ELE. Cuadernos de didáctica del español/LE. Arco/Libros. Madrid.

RICHARDS, J C. y ROGGERS, T S. (1986). Approaches and Methods in Language Teaching. Cambridge LanguageTeaching Library. UK

VAN EK, J, A. (1975). Systems development in adult language learning. The threshold level http://files.eric.ed.gov/fulltext/ED108482.pdf (acceso el 20/12/2016).

WILliAMS, M. y BURDEN, L. (1999). Psicología para profesores de idiomas. Enfoque del constructivismo social. Editorial Edinumen. Madrid.

WILLIS, J. (2007). Doing Task-based Teaching OUP. British Council. https://www. teachingenglish.org.uk/article/criteria-identifying-tasks-tbl (acceso el 04/12/2017)

WILLIS, J. (2016). Doing Task-Based Teaching. Oxford Handbooks for Language Teachers. Oxforr University Press. UK.

YALDEN, J. (1983). The Communicative Syllabus. Evolution, Design and Implementation. Practice-Hall International English Language Teaching. Exeter. UK.

Recebido: 21/06/2017

Aceito: 13/11/2017 